Article

\title{
Urban thermal environment and heat island in Ho Chi Minh City, Vietnam from remote sensing data
}

\author{
Tran Thi Van*, Ha Duong Xuan Bao, Nguyen Thi Tuyet Mai \\ 1 Ho Chi Minh City University of Technology, Vietnam National University Ho Chi Minh City; \\ tranthivankt@hcmut.edu.vn \\ * Correspondence: tranthivankt@hcmut.edu.vn; Tel.: +84-919-188-485
}

\begin{abstract}
In urban area, one of the great problem is the rise of temperature, which leads to form the urban heat island effect. This paper refers to the trend of the urban surface temperature extracted from the Landsat images from which to consider changes in the formation of surface urban heat island for the north of Ho Chi Minh city in period 1995-2015. Research has identified land surface temperature from thermal infrared band, according to the ability of the surface emission based on characteristics of normalized difference vegetation index NDVI. The results showed that temperature fluctuated over the city with a growing trend and the gradual expansion of the area of the high-temperature zone towards the suburbs. Within 20 years, the trend of the formation of surface urban heat island with two typical locations showed a clear difference between the surface temperature of urban areas and rural areas with space expansion of heat island in 4 times in 2015 compared to 1995. An extreme heat island located in the inner city has an area of approximately $18 \%$ compared to the total area of the region. Since then, the solution to reduce the impact of urban heat island has been proposed, in order to protect the urban environment and the lives of residents in Ho Chi Minh City becoming better.
\end{abstract}

Keywords: emissivity; land cover; land surface temperature; surface urban heat island; thermal environment; mitigation

\section{Introduction}

Urban development is recognized as development in urban economy, urban culture, urban ecological environment, urban infrastructure and management. A corollary of this development is to change the quality of the environment, especially to create differences in microclimate conditions of the urban environment. As a result of urban development, natural landscapes are affected, water surface is shrunk, and agricultural land is switched to construction land, consequently, leading to appear more and more impervious surfaces, which is the typical cover of urban environment. These impervious surfaces cause to change thermal property of the soil, heat budget of Earth's surface and surface energy budget in the earth, to alter the nature of the atmospheric circulation around. These phenomena generate a large amount of waste heat from human activities, which leads to a series of changes in the system of the urban environment. The impact of urban development on heat environment is to create effect as "Urban Heat Island" (UHI). This effect occurs when at the same time, the average temperature in the area of urban development with construction works is higher than that in the area of the park and the surrounding countryside, which causes the phenomena as surface thermal radiation anomalies. In essence, the impervious surfaces (concrete, asphalt, car park...) absorb solar radiation and transfer into the heat energy. A portion of this heat is transmitted through the impermeable surface layer and into the environment beneath the surface, partly reflected back into the air above in the form of latent heat. Surface thermal radiation anomalies will spread upwards under the impact of convection currents in the atmosphere, heat the air layer above and alter atmospheric circulation conditions, as a result of impact on regional climate, causing extreme weather patterns and change the composition of the aerosols [6-7]. The difference of surface 
temperature between these urban-rural areas may fluctuate from $5-7^{\circ} \mathrm{C}$ [13], sometimes rise to $11-$ $12^{\circ} \mathrm{C}[20]$ or $11-15^{\circ} \mathrm{C}[15]$.

Monitoring land surface temperature (LST) plays a crucial role in the research of UHI. LST is directly linked to surface radiation and energy conversion, nature of climate and human's activities [25]. Before the advent of remote sensing technology, UHI was studied with the observation on the in-situ stations or the thermometer attached on motorbikes [23]. With the advent of satellite and aircraft, thermal infrared remote sensing has provided the new development for the study of UHI.

$\mathrm{UHI}$ is a general concept and is also called the heat island by using monitoring data of air temperature, measured at a height of $2 \mathrm{~m}$ above the ground. Results of remote sensing image analysis will produce surface temperature value of ground objects, so the heat island will also be considered related to the concept of "urban heat island surface" (SUHI). So the presentation of UHI, related to remote sensing techniques definitely mentions about SUHI.

SUHI was first studied by Rao in 1972 with the satellite data. Later on, several researches were performed to assess SUHI spatial model by extracting LST and examine their relationship with the characteristics of the land cover and land use [11]. The further investigation showed that climate change on urban temperature, are related to surface features, such as the NDVI [10, 24] was used to evaluate the relationship between LST and vegetation development in the urban areas on various scales. The results showed the importance of the extent and impact model, while evaluating their relationship. The analysis then figured out the source of SUHI born related to the surface shape and surface thermodynamic properties [23].

In Vietnam, recently there have been a number of studies, which apply remote sensing to evaluate the urban thermal environment by estimating the temperature value from the satellite images. An experiment on the radiant temperatures from the ASTER images was carried out for Ha Noi central area in 2003 [16]. Tran Thi Van (2006) [19] explored the thermal band from LANDSAT ETM+ images to calculate the temperature distribution in 2005 in northern area of Ho Chi Minh City. Le Van Trung and Nguyen Thanh Minh (2006) [8] calculated to publish the temperature map for the whole Ho Chi Minh City using NOR and REF methods. Other authors [5, 7] applied satellite images to measure the temperature on each type of land cover. In 2011, Tran Thi Van and colleagues [20] had another detailed study on estimating actual surface temperature and determined the relationship between temperature change and urbanization factors. Meanwhile, several examinations on SUHI features during 1989-2006 illustrated the difference which made up SUHI in HCMC was approximately $11-12^{\circ} \mathrm{C}$.

This article presents the application of remote sensing technology from exploring the Landsat satellite images with reflectance and thermal infrared bands to investigate the development of thermal environment through SUHIs; thus, proposing the solutions to minimize their impact on urban environment and human health in Ho Chi Minh City (HCMC) during 1995-2015. In the context of apparent climate change, along with fast and complicated urbanization, comprehensive understanding on UHI will assist to effectively manage urban environment and protect community health from their impact.

\section{Study Area}

HCMC is located in the eastern part of South Vietnam, with the area of $2098.7 \mathrm{~km}^{2}$ accounting for $0.76 \%$ of the whole country (Figure 1). The distribution of residents in HCMC is uneven. While the population density of districts 3, 4, 10 and 11 is up to 40,000 people $/ \mathrm{km}^{2}$, Can Gio as suburban district has the population density of only 98 people $/ \mathrm{km}^{2}$. From 1986 to now, when the city entered a period of renovation, the influx of immigrants from other provinces has converged on more and more to make a living. In the years 1991-1994 when the country began to exit the socio-economic crisis and gradually restore the economy, the pressure on immigrants to city was even stronger. According to the forecast until 2025, HCMC has 10 million people, and will be a dynamic megacity [12]. The increase in population and socio-economic development has led to increase traffic, expand housing area to the suburbs more than before. The higher the building density is, the higher surface radiation temperature will be. Meanwhile, the green area of the city is narrowed. The natural balance is 
disrupted, leading to a strong impact on the micro climate change, reflected in the increase in urban temperatures when compared to the surrounding suburbs, thereby creating UHI effect, making the city turn into a "fireball" heated people [20].

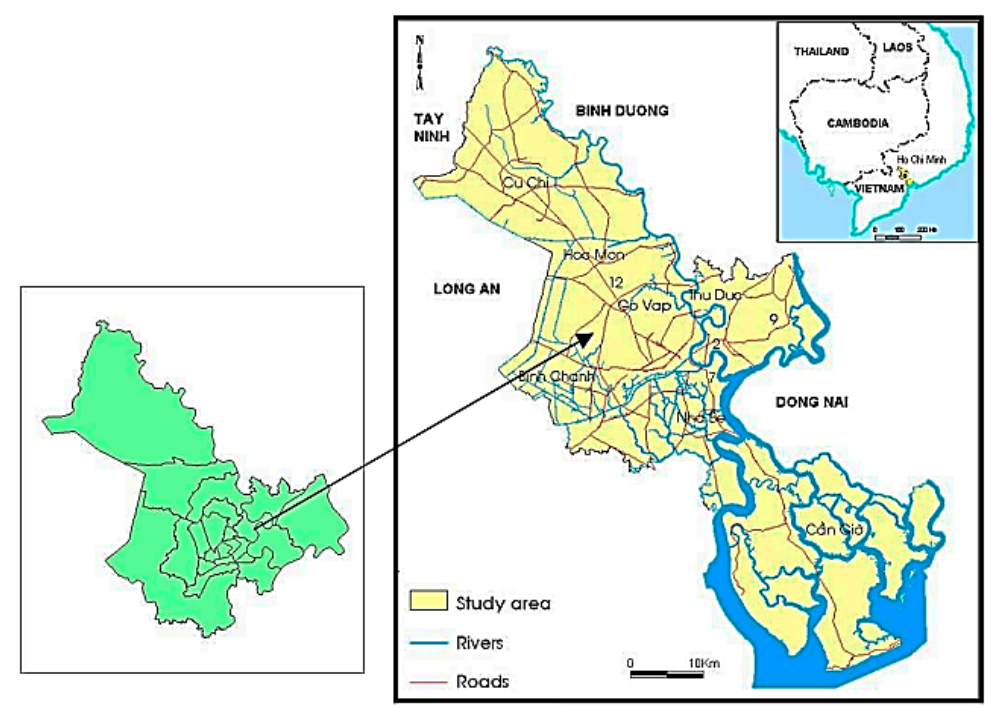

Figure 1. Study area in Ho Chi Minh City

\section{Methodology}

There are two approaches to solve the problem when researching on UHI. The first approach is to use the ground observation data from meteorological stations distributed over a distance between them; thereby to evaluate temperature fluctuations in each station, or interpolate from a few stations on the territory. Another method is to use the satellite data, extracting temperature information from images by processing methods and calculations. As explained previously, the second method shows the spatial distribution of temperature across the region in each grid cell, depending on the size of the pixel. This gives more accurate results than interpolation for a large area from a few points only. Therefore, the method of this study is to go towards using satellite imagery.

Thermal infrared radiation in the range of $8-14 \mu \mathrm{m}$, emitted from the surface is correlated with kinetic temperature and surface emissivity. However, there are two main issues to be addressed to achieve the temperature and surface emissivity from thermal infrared data. First, the radiation measured at the sensor is affected by the atmosphere from the absorption and re-emission by gases, mainly water vapor in the infrared region of the electromagnetic spectrum. Therefore, to achieve surface temperatures, it is necessary to do atmospheric correction by using radiative transfer models. The second is unidentifiable nature of the measurements of temperature and emissivity. If thermal radiation is measured in $\mathrm{N}$ bands, there will be $\mathrm{N}+1$ unknown parameters including $\mathrm{N}$ layer of emissivity (for N-band) and 1 layer of surface temperature. The estimate of emissivity and temperature data in multispectral thermal infrared data requires additional assumptions to solve the unknown variable $[9,11]$. The assumption is often related to the emission measurements in the laboratory or in the field.

Radiation values obtained in the thermal infrared band of the electromagnetic spectrum on the satellite sensor is calculated through the radiative transfer equation. Actual calculation for natural surfaces, surface radiation is approximately represented by an formula

$$
\mathrm{R} \lambda=\varepsilon \mathrm{B} \lambda
$$

\subsection{Derivation of LST}

In the thermal infrared remote sensing, radiation temperature $\left(T_{R}\right)$ is defined as the temperature equivalent to that of the black body, transmitting the same amount of radiation received from a real object and depended on real surface dynamic temperature ( $\left.\mathrm{T}_{\mathrm{K}}\right)$ and emissivity. In case it is not 
blackbody, the total amount of emitted radiation (B) is expressed in the Stefan-Bolzman law as follows [4]:

Inferred,

$$
\mathrm{B}=\varepsilon \sigma \mathrm{TK}^{4}=\sigma \mathrm{T}_{\mathrm{R}}{ }^{4}
$$

Radiation temperature measured by the sensor on the satellite known as brightness temperature of blackbody Тв (with $\varepsilon=1$ ) and is determined by Planck's law:

$$
\mathrm{T}_{\mathrm{B}}=\frac{\mathrm{K}_{2}}{\ln \left(\frac{\mathrm{K}_{1}}{\mathrm{~B}_{\lambda}}+1\right)}
$$

Where, $\mathrm{B}_{\lambda}$ is blackbody radiance $\left(\mathrm{Wm}^{-2} \mu \mathrm{m}^{-1}\right) ; \mathrm{K}_{1}=2 \pi \mathrm{hc}^{2} / \lambda^{5} ; \mathrm{K}_{2}=\mathrm{hc} / \mathrm{k} \lambda ; \mathrm{h}$ is Planck's constant $\left(6.62 \times 10^{-34} \mathrm{~J}\right.$-sec); $\mathrm{c}$ is velocity of light $\left(2.998 \times 10^{8} \mathrm{~m} \mathrm{sec}^{-1}\right) ; \lambda$ is wavelength of emitted radiance $(\mathrm{m}) ; \varepsilon$ - object emissivity; $\sigma$ is the Stefan Boltzmann constant $\left(5.67 \times 10^{-8} \mathrm{Wm}^{-2} \mathrm{~K}^{-4}\right)$.

The surface temperature is kinetic temperature of an object, and can be measured with a thermometer. Formula (3) shows that, between the radiation temperature and surface temperature there have a relationship through the emissivity $\varepsilon$. Brightness temperature $T_{B}$ is already known, the problem is to determine the emissivity $\varepsilon$, from which to infer the surface temperature Ts. At this time, the surface temperature $T_{S}$ (meaning LST in general) will be determined with $T_{S}=T_{K}$ and $T_{B}=T_{R}$

$$
\mathrm{T}_{\mathrm{S}}=\frac{1}{\varepsilon^{1 / 4}} \mathrm{~T}_{\mathrm{B}}
$$

This indicates that the temperature measured by remote sensing methods will be smaller surface dynamic temperature equivalent by coefficient $1 / \varepsilon^{1 / 4}[4]$. If the total radiation emitted from the ground can be measured, or if the radiation temperature measured data can then be used to calculate the surface temperature.

\subsection{Estimation of surface emissivity}

Emissivity $(\varepsilon)$ is the ratio of the energy radiated from natural surfaces divided by the energy emitted from a black body at the same wavelength and temperature (Formula 1). Temperature and emissivity are two variables that should determine in remote sensing methods, so these methods are often developed simultaneously calculate the value of these two variables. Due to the complexity and undefined, the problem of the $\mathrm{N}+1$ unknowns are not resolved with precision and full generality. Emissivity surface is variable, less changed over time and space than the surface temperature, so it is common to determine the emissivity surface before the surface temperature calculation [21].

NDVI based method is useful if the emissivity of bare soil and vegetation, as well as the structure and distribution plants are known in advance. Estimating the surface emissivity from the visible channel and near-infrared method NDVI has 2 main advantages: (1) The at-satellite sensors typically provide spatial resolution of the visible and near-infrared bands higher than of the thermal infrared band, so obtained emissivity images will own spatial resolution higher than the results from the calculation methods directly from the thermal infrared band; (2) NDVI method can be applied to any sensor without depending on the amount of thermal infrared band.

The pixels representing the land surface is usually mixture pixel containing both plants and soil and depending on the resolution of satellite images. Effective emissivity of a pixel can be estimated by adding up the contributions of plant and soil emissivity contained in that. Van de Griend and Owe (1993) [22] carried out experiments by directly measuring emissivity and reflectance in the visible and infrared spectrum for areas with homogeneous characteristics to calculate NDVI and found empirical relationship between emissivity and NDVI.

$$
\varepsilon=1.0094+0.047 * \ln (\mathrm{NDVI})
$$


Valor and Caselles (1996) [21] developed another method to calculate emissivity from NDVI values according to the following equation:

$$
\varepsilon=\varepsilon_{\mathrm{v}} \mathrm{P}_{\mathrm{v}}+\varepsilon_{\mathrm{s}}\left(1-\mathrm{P}_{\mathrm{v}}\right)
$$

Where $\varepsilon_{v}$ and $\varepsilon_{s}$ are the emissivites of the full vegetation cover area and pure bare soil, ie within one pixel representing only the plant or just the bare soil with no mixing. $P_{v}$ is the proportion or fraction of the vegetation presenting in pixel and has value between 0 (for bare soil) to 1 (for full vegetation cover area). $P_{v}$ can be calculated according to the correlation of NDVI with the threshold value of the bare soil NDVIs and full vegetation NDVI $\mathrm{v}_{\mathrm{v}} \mathrm{P}_{\mathrm{v}}$ is determined by the formula ratio [1] as follows:

$$
P_{v}=\left(\frac{N D V I-N D V I}{s}\right)^{2}
$$

Where NDVI is determined by the ratio of the reflectance values in the range of visible red channel and the near-infrared ((red-NIR)/(red+NIR)).

In this study, we have tested in HCMC with sample areas just as vegetation and bare soil, with the size much bigger than one pixel to determine NDVI of soil and vegetation; then, have determined the emissivity of soil and vegetation from the empirical formula of Van de Griend and Owe (1993) [22], then have calculated the fraction of vegetation cover $P_{v}$ to provide input for Valor and Caselles method to determine the emissivity for each pixel of the study area.

Satellite images taken in this study were Landsat TM, ETM + and OLI \& TIRS, obtained free of charge from the website of the United States Geological Survey (USGS). They were acquired on February 02, 1995 (TM); January 04, 2005 (ETM+); and January 24, 2015 (OLI \& TIRS). Besides, topographic base map at scale 1: 25,000 was collected to provide topographical information about hydrographic network, roads, industrial areas and administrative boundaries.

\section{Results and Discussion}

\subsection{Distribution of LST in 1995-2015}

Evaluate the accuracy in determining satellite image-based temperature is essential to control the precision of results. At the national meteorological station, the air temperature is measured 8 times a at the hour of $1,4,7,10,13,16,19$ and 22. Meanwhile, land surface temperature is only measured 4 times a day at the hour of $1,7,13$ and 19, no measurements at 10 am when the satellite passed. Therefore, the evaluation of error for the study of heat from satellite data is always limited without long time to manually perform observed experiments on the ground at the time of satellite acquisition. Additionally, when evaluating changes in the use of historical materials, it is even more difficult due to absolutely no ground temperature measurements in parallel with the satellite. When designing a sensor to measure surface temperature, experts have done a lot to verify the accuracy of the equipment before officially operating the equipment. Studies have demonstrated that the error in determining the temperature from satellite images ranges from $0.5-2^{\circ} \mathrm{C}$ when implementing the full atmospheric correction and depending on the different calculation methods [3]. According to a study by [20], with the establishment of 10 monitoring points for proofs, and they have determined the error for this method of determining temperature is $\pm 1.95^{\circ} \mathrm{C}$. Therefore, the method of determining the surface temperature from satellites is reliable and can be used to support monitoring environmental problems and climate change, in conditions lacking measuring ground station network.

Emissivity $(\varepsilon)$ is related to the state of the land cover and proportional to the vegetation biomass. The results determine the emissivity shows, vegetated areas with average coverage usually have $\varepsilon>$ 0.92 . The vegetated areas with dense coverage usually own $\varepsilon>0.95$, there are agricultural land with a high density of trees or the green park areas. Vacant land areas, urban and construction zones usually have $\varepsilon$ ranging in $0.90-0.91$. The emissivity of water bodies, rivers and lakes ranges in 0.910.92 expressing the dependence of the presence of vegetation. In general, the surface emissivity in 
0.90-0.92 tends to expand gradually from the inner city to the north of the city, belonging $\mathrm{Cu} C h i$ and Hoc Mon districts; to the west of the city, belonging Binh Chanh district; to the east of the city as District 9. These are the city's suburban areas. This is synonymous with the decline of the plant presence in the land cover when the values $\varepsilon>0.95$ and $\varepsilon>0.92$ are a gradual reduction in terms of spatial distribution (Figure 2).

The LST distribution results (Figure 3) show that, in general, higher temperatures are concentrated in the inner city and districts of the northern city with value ranged from 21 to $47^{\circ} \mathrm{C}$. LST values, higher than $40^{\circ} \mathrm{C}$, were scattered in industrial and production areas, such as Tan Thuan export processing zones, industrial parks Linh Trung and Tan Binh.

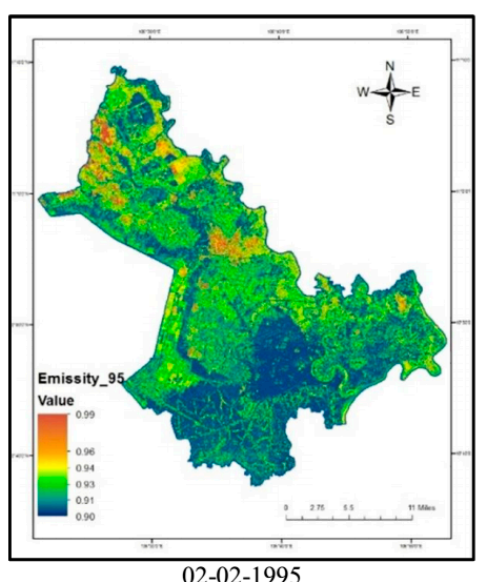

02-02-1995

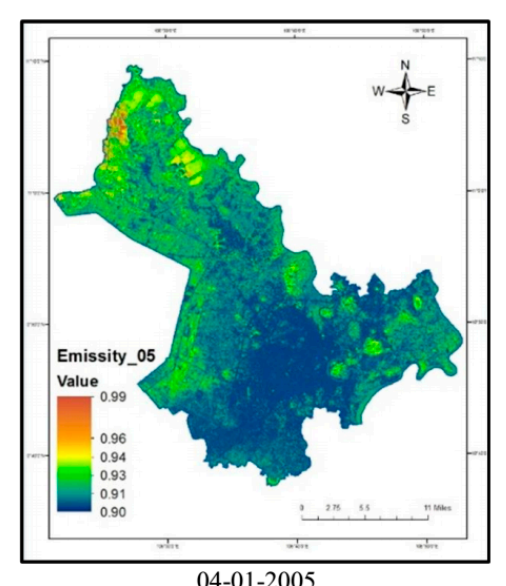

04-01-2005

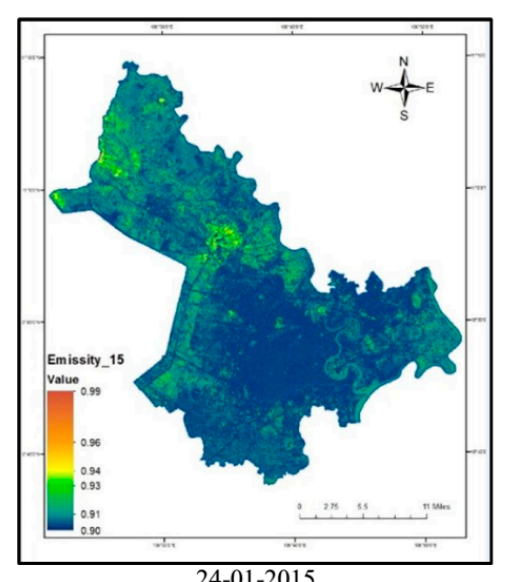

24-01-2015

Figure 2. The surface emissivity at the time of satellite images acquisition in period 1995-2015

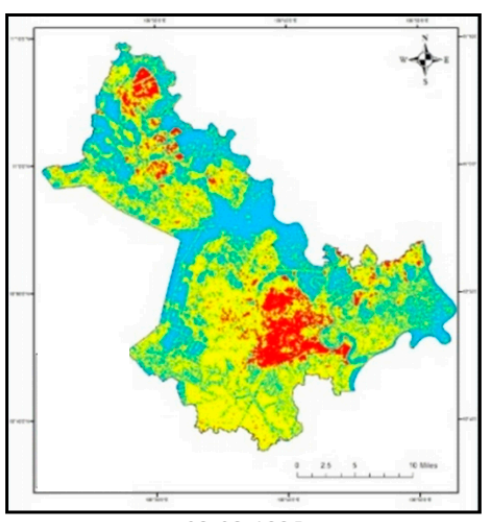

$02-02-1995$

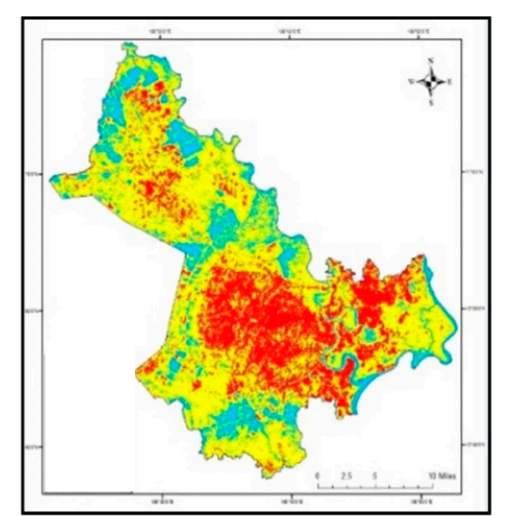

04-01-2005

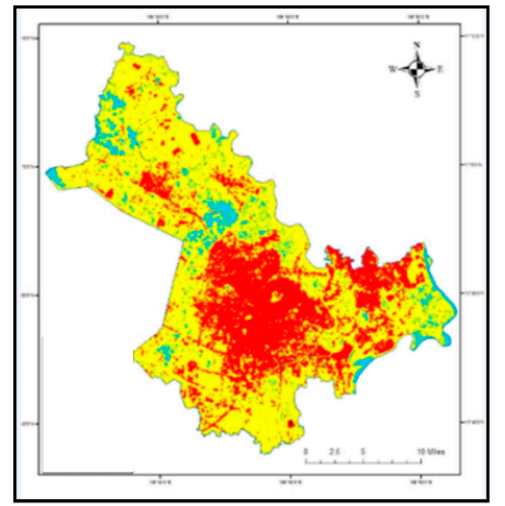

24-01-2015

$$
20-30^{\circ} \mathrm{C} \square 30-35^{\circ} \mathrm{C} \square 35-40^{\circ} \mathrm{C} \square>40^{\circ} \mathrm{C}
$$

Figure 3. LST at the time of satellite images acquisition in period 1995-2015

Most of the north of HCMC owns temperatures from 35 to $40^{\circ} \mathrm{C}$, mainly concentrated in the central area, residential area lacking trees or with sparse density, and the vacant area, corresponding to the decline in vegetation cover as well as the surface emissivity, such as district 10, Go Vap district, district 11, Tan Phu... This can be explained that in urban areas the buildings are usually constructed from impervious materials such as concrete, stone, asphalt, tile roof... which has high thermal conductivity properties, good and fast radiation absorber properties, but low reflectivity. Meanwhile, the evaporation process of impervious surface from these materials is less than the surface covered with vegetation, trees or moisture soil [20].

The LST ranged from 30 to $35^{\circ} \mathrm{C}$ concentrated in the area of trees, meadows and agricultural land, mainly in $\mathrm{Cu} C h i$ and Binh Chanh District, and part of Hoc Mon District. In this area manufacturing activity is mainly agriculture, rice and food crops. LST value range lower $30^{\circ} \mathrm{C}$ is as forests, water and riparian areas Saigon. LST on water is usually from 20 to $30^{\circ} \mathrm{C}$. 
The images were taken in the dry season of HCMC (in January and February of the year), so they clearly show the temperature of the dry season. However, due to different months and different acquired date the LST distribution also differs on the comparison of satellite images in the same area as in agricultural areas. On the other hand, the LST distribution depends on the weather, the planting season and soil moisture, expressed as, land under crops, land covered with vegetation, or land be harvested crop or vacant land. Specifically, on a satellite image acquired on January 04, 2005, as the influence of the cool weather, agricultural land in the districts of Binh Chanh, $\mathrm{Cu} C h i$ and Hoc Mon persists vegetation cover, leading LST in some areas to fluctuate between $20-30^{\circ} \mathrm{C}$. In addition, this is also the time of crops in the maturity period, so the ability to evaporation cooling surroundings is also limited than growth stages. Therefore, some parts of the suburbs surfer the high LST from 35 to $40^{\circ} \mathrm{C}$. The last days of January and early February is the beginning month of the dramatic hot season and harvest of agricultural crops, food crops and rice. Some areas of agricultural land in the suburbs like $\mathrm{Cu}$ Chi, some communes in Hoc Mon and Binh Chanh Districts are areas with crops in maturity stage, or harvested and became vacant land. Therefore, high LST oscillated between $30-35^{\circ} \mathrm{C}$, which is shown in January's image of 2005 and 2015. For February-1995 image, this is the period which entered the hot season. However, in this stage the area of impervious surface coverage was not high, the urbanization rate was slow, so LST range $35-40^{\circ} \mathrm{C}$ was concentrated in urban areas. The suburban area of $\mathrm{Cu}$ Chi District with LST above $35^{\circ} \mathrm{C}$ concentrated in the communes such as An Phu, Phu My Hung and An Nhon Tay, was the bare land after crop harvest. In general, the agricultural lands in suburban express LST changed according to seasonal conditions and existing plant above the soil, while in any month of the year as well as at different stages the urban area has always shown a higher temperature than the surrounding area (Figure 4)
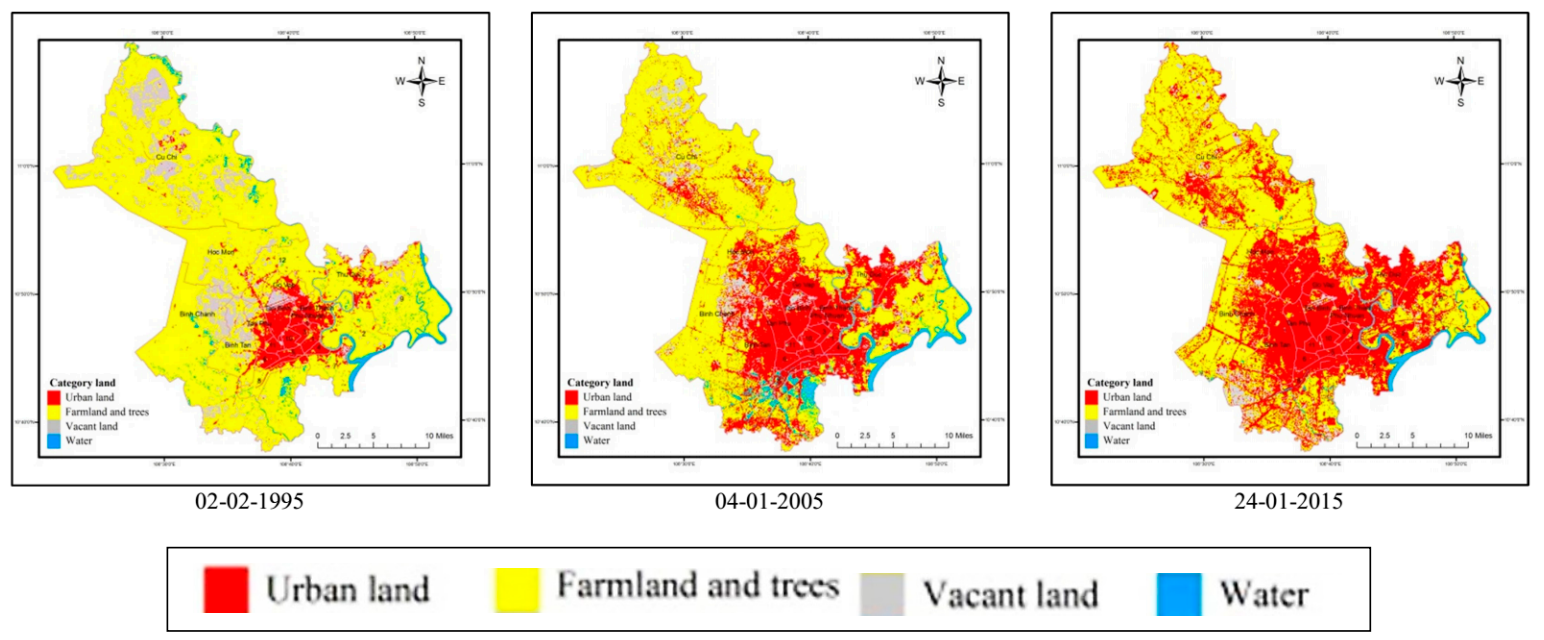

Figure 4. Land cover at the time of satellite images acquisition in period 1995-2015

\subsection{LST tendency during 1995-2015}

Considering satellite images taken at 3 different moments in 1995, 2005 and 2015, the average LST entire north region of HCMC increased over time from $30.79^{\circ} \mathrm{C}$ in 1995 to $33.51^{\circ} \mathrm{C}$ in 2015 . LST trend for the whole region as well as the inner city and suburban, tends to increase (Table 1). Investigating average LST for each district, the highest average LST usually falls in the districts such as Tan Phu, Tan Binh, District 6, District 4, and Go Vap (from 33 to $37^{\circ} \mathrm{C}$ ). Meanwhile, lower average LST usually falls in suburban districts, such as the Cu Chi, Hoc Mon, Binh Chanh, District 2 and District 9 (from 29 to $33^{\circ} \mathrm{C}$ ).

The total area of research area is 129,116 ha. As a whole, the area with LST ranging from 20 to $30^{\circ} \mathrm{C}$ decreased from $38.4 \%$ in 1995 to $6 \%$ over the whole area in 2015. Meanwhile, the area with LST ranging over $35^{\circ} \mathrm{C}$ increased from $7.8 \%$ in 1995 to nearly $30 \%$ by 2015 . This represents an area with LST ranging from $20-30^{\circ} \mathrm{C}$ LST has moved to the area with LST above $35^{\circ} \mathrm{C}$ (Table 2)

Table 1. Average LST ( $\left.{ }^{\circ} \mathrm{C}\right)$ in 1995-2015 


\begin{tabular}{cccc}
\hline Average LST (oC) & $\mathbf{1 9 9 5}$ & $\mathbf{2 0 0 5}$ & $\mathbf{1 / 2 0 1 5}$ \\
\hline Whole northern part of HCMC & 30.79 & 32.78 & 33.51 \\
Area with 19 inner-city districts & 31.61 & 32.74 & 34.50 \\
Area with 3 suburban districts & 30.27 & 31.67 & 32.89 \\
\hline
\end{tabular}

Table 2. Area percentage (\%)corresponding with each LST level in 3 acquired times during 19952015

\begin{tabular}{cccc}
\hline \multirow{2}{*}{ T (oC) } & \multicolumn{3}{c}{ Year } \\
\cline { 2 - 4 } & $\mathbf{1 9 9 5}$ & $\mathbf{2 0 0 5}$ & $\mathbf{2 0 1 5}$ \\
\hline $20-30$ & 38.4 & 17.6 & 6.0 \\
$30-35$ & 53.8 & 71.6 & 64.1 \\
$35-47$ & 7.8 & 10.8 & 29.9 \\
\hline
\end{tabular}

In 1995 , the majority of area was manipulated at LST ranging $30-35^{\circ} \mathrm{C}$ accounting for $53.8 \%$ of total area, followed by area with LST $20-30^{\circ} \mathrm{C}$ accounting for $38.4 \%$ of total area. These two areas with such LST levels majorly located in suburban and rural areas. On the contrary, LST over $35^{\circ} \mathrm{C}$ was mainly in urban core which accounted for $7.8 \%$ of total area.

Comparing to 1995 , in 2005 the majority of area was manipulated at LST $30-35^{\circ} \mathrm{C}$ accounting for $53.8 \%$ of total area and increased $17.8 \%$. Area with LST $20-30^{\circ} \mathrm{C}$ accounting for $17.6 \%$ of total area, decreased $20.8 \%$. Area with LST over $35^{\circ} \mathrm{C}$ accounted for $10.8 \%$, increased $3 \%$. In conclusion, the area with LST $20-30^{\circ} \mathrm{C}$ switched to area with LST $30-35^{\circ} \mathrm{C}$ and that with LST over $35^{\circ} \mathrm{C}$. The area with increased LST focused in urban core, residential areas and industrial parks.

Similar to 2005, in 2015 space area has tended to increase along with the increase of LST. In particular, the area with LST above $35^{\circ} \mathrm{C}$ accounted nearly $1 / 3$ of the entire study area (29.9\%), while the area with cooler temperatures $\left(20-30^{\circ} \mathrm{C}\right)$ retained only very few $(6 \%)$. This represents an expansion of the size of the area with the increasing temperature, mainly from the urban core to new surrounding developing urban, and the heat is gradually covered most of the central area of HCMC

\subsection{SUHI change during 1995-2015}

The intensity of UHI is determined by the interaction of several factors, including the degree of urbanization (total built-up area, population size, industrial development and transportation), the geometry of a city, physical environment and human activities [26]. The UHI effect is linked to the composition of underlying surface, i.e. the pattern and structure of land use and land cover. Urban development has often intensified the degree of UHI. UHI is a general concept and is also called the heat island by using monitoring data of air temperature, measured at a height of $2 \mathrm{~m}$ above the ground. Results of remote sensing image analysis will produce surface temperature value of ground objects, so the heat island will also consider related to the SUHI.

LST above $35^{\circ} \mathrm{C}$ quite clearly reflects the nature of SUHI for the difference between urban and rural areas in HCMC. Besides, the LST from $35^{\circ} \mathrm{C}$ dramatically affect the lives of local communities, causing muggy weather, discomfort and increase the cooling operation, which generated environmental pollutants. So to assess SUHI, LST threshold is chosen as above $35^{\circ} \mathrm{C}$ and is used to calculate the magnitude of SUHI on the north region of HCMC. Figure 5 identified two distinct SUHIs formed in the study area. The SUHIs tend to expand in size and were demonstrated in Table 3 and Figure 6 in terms of their spatial distribution

Table 3. SUHI magtnitude (ha) with LST $>35^{\circ} \mathrm{C}$

\begin{tabular}{lcccc}
\hline \multirow{4}{*}{ SUHIs } & Feb. 2, 1995 & Jan. 4, 2005 & Jan. 24, 2015 \\
\cline { 2 - 5 } & Area (ha) \% total area & Area (ha) $\%$ total area & Area (ha) $\%$ total area \\
\hline
\end{tabular}




\begin{tabular}{ccccccc}
\hline SUHI_1 & 6,637 & 5.14 & 19,696 & 15.25 & 23,757 & 18.40 \\
SUHI_2 & 539 & 0.42 & 3,814 & 2.95 & 4,844 & 3.75 \\
Total & 7,176 & 5.56 & 23,510 & 18.21 & 28,601 & 22.15 \\
\hline
\end{tabular}
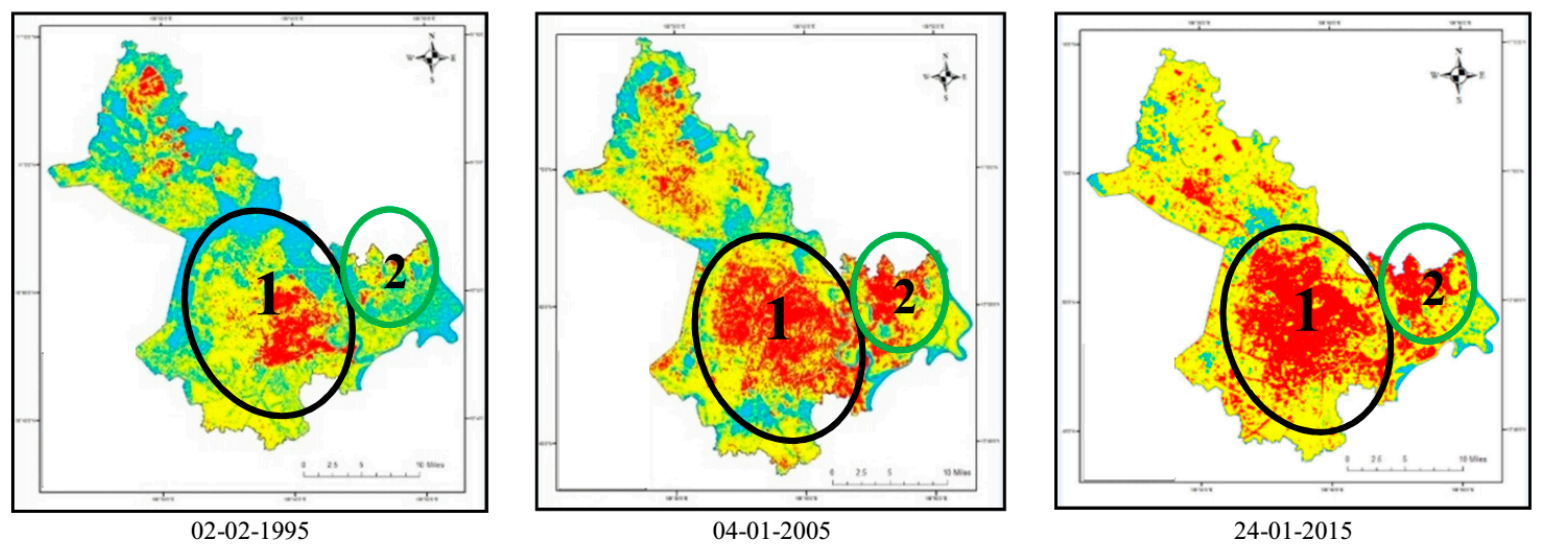

\section{$20-30^{\circ} \mathrm{C} \square 30-35^{\circ} \mathrm{C} \square>35^{\circ} \mathrm{C} ; \quad \mathbf{1 , 2}$ - SUHIs}

Figure 5. Location of typical SUHIs in the northern part of HCMC at the time of satellite images acquisition

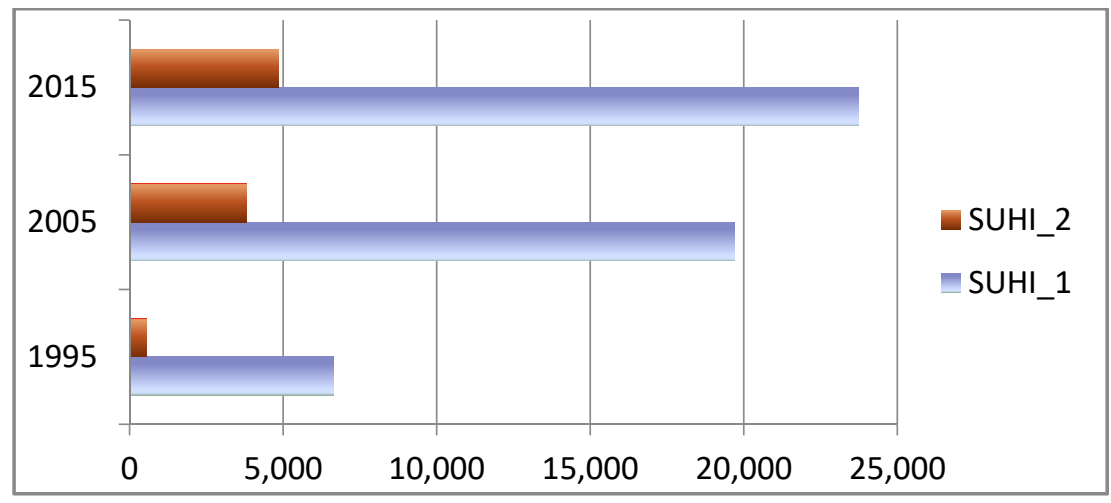

Figure 6. SUHI magnitude change at the time of satellite images acquisition

According to the spatial pattern of LST at 3 acquired images, SUHI has changed and expanded significantly from dot patterns or small scattered regions in 1995 to the a more contiguous pattern in chains or focus area, grew to 2005, and from 2005 to 2015, especially in the inner city if dropped areas with high LST in the agricultural vacant land of Binh Chanh district in the southwest and the Cu Chi district in the north of HCMC. Total area of SUHI in the whole region was extended from 7.972 ha in 1995 to 24.464 ha in 2005, increased 3 times. In 2015 SUHI magnitude was expanded up to 31.495 ha, increased 4 times compared with 1995.

Pictures of the expansion trend of the LST over $35^{\circ} \mathrm{C}$ in central urban areas during the period from year 1995 to 2005 has demonstrated that the land use change and impervious surface increase caused by the process of urbanization. According to statistics from 2001 to 2005 there were over 8,000 hectares of agricultural land in the new districts as districts 2, 7, 9, 12 and Thu Duc district which have been converted into residential land and some areas uncontrolled self-developed urban areas at this stage. On the other hand the process of urbanization has been rapid in many districts of the City as the new District 2, 7, 9, 12, Binh Tan, Tan Phu, Thu Duc, and many new urban areas such as Phu My Hung, Thu Thiem, South Saigon, Phuoc Hiep also been set up to 2003. This reflects the rapid 
development and transformation of urbanization 1995-2005. Besides, many self-developed residential areas have been formed in many wards and communes, where previously existed as the rural, such as Phu My ward (District 7), Trung My Tay ward (District 12). The unsuitable land use planning and building has depleted natural surface area and increased impervious surface area. In the process of development of urban areas such as Phu My Hung in District 7, Bau Cat in Tan Binh, Phu Lam in District 6, many low-lying swamps (canals, lakes and ponds) were leveled to extend the construction ground. Along with the expansion of urban space, the strong industrialization has also occurred as export processing zones and industrial zones, with the advent of the Tan Thuan Export Processing Zone in District 7 on the plot 300 ha in 1991, Linh Trung industrial zone in Thu Duc, Tan Tao industrial zone in Binh Chanh district, etc... Up to May 2006, the city has 13 industrial parks, 3 export processing zones and 1 high-tech zone in 2068 hectares [18]. This may explain the relatively large changes in the SUHI area expansion towards the suburbs (Figure 5).

Typically in the study area there are 2 large SUHIs significantly developed within 20 years. The first huge SUHI was formed in the urban core from an area of 6.637 ha in 1995, then to 2005 the area of 19.696 ha was reached, increased 3 times, and in 2015 expanded up to 23.757 ha, up 3.6 times compared to 1995 and accounted for approximately $18 \%$ compared to the total area of the north region of HCMC. The area expansion of the LST above $35^{\circ} \mathrm{C}$ here was explained due to the increase of impervious surface area plus the high speed of urbanization and population growth in this period.

The 2nd SUHI was formed in Thu Duc District located in the eastern part of HCMC, where there was the production of Linh Trung Industrial Park and Hi-Tech Park in District 9 as well as population growth, increased housing density. In 1995 the region with high temperatures could not be determined, the fact that there was only a few small scattered locations. However, until 2005 and 2015, there has been a distinct regions formed with LST value higher than surrounding area, and spatial SUHI area has been expanded with the ratio of 9 times compared with 1995.

In addition, there still exist some small scattered SUHIs in the north of the city, belonging to $\mathrm{Cu}$ Chi district, but they are not significant, since this place is still a large area of agricultural land and forests. This clearly shows the important role of vegetation cover in regulating thermal environment over a territory.

\subsection{Solution to mitigate the formation and impact of urban heat island}

Apart from certain positive impact, UHI was majorly known as the cause of negative effects on environment and human in various aspects. High temperature from UHI in urban, especially in summer, might affect environment and life quality as a result of high demand of electricity, energy for air conditioners. This situation leads to increase hazardous gas emission and cause air pollution. The consequences are seen as damaging human's health such as respiratory system, heat cramp and strokes, which imposes pressure on health system. Likewise, UHI raises the water usage demand and threatened water quality. Because of using energy for air conditioners and using water as a source of daily activities, water shortage is inevitable. As the temperature of water increased, aquatic life is influenced in terms of metabolism and reproduction of many aquatic species under water. More importantly, UHI also largely impacts climate change due to proliferation of air pollution and "greenhouse" effects [2].

HCMC is a large dynamic urban also known as economic-social-cultural center of Vietnam. For years, the city is continuing to expand into the suburbs and to develop rapidly. Therefore, it is necessary to have effective urban management strategy to have a quality life for the community. The purpose of this solution is to boost the process of cooling in urban environment to reduce the UHI impact. On the other hand, certain benefits were recognized such as reduce the energy consumption, air pollution and emission of greenhouse gas. By the research result, high temperature is known to exist where the surface land is covered by concrete, construction materials, traffic rout and places with low density of plants, lack of cooling shadows, water surface, and finally where the vogue of human activities. As a result, certain proposed solutions are made to decrease the impact to proliferation of temperature such as: (1) The larger green space area is, the cooler surrounding one becomes, thereafter the temperature will lower at night; (2) better ventilation would lead to reduce 
temperature, cooling efficiency will be higher; (3) the greater open water surface is widen, the higher cooling efficiency will be; (4) integrating the three principles on the effectiveness will make urban cooling capacity increased.

Besides, solutions for environment management should gain a considerable amount of attention. Urban heat environment is the result of general impact from manufacturing and human activities, and is influenced by many elements of society. To limit urban temperature and avoid UHI effect, it is necessary to tightly collaborate with agents such as governments, policy makers, Department of urban planning architecture and environmentalists, manufacturing and business representatives, economic organizations and investors, plant companies, and community representatives. Each party plays an important role in managing environment to limit the impact of UHI and enhance urban environment quality.

\section{Conclusions}

All the analyses in this paper were based on the interpretation of remote sensing images, by which the characteristics of urban thermal environment and SUHI in HCMC showed clear images of the distribution as well as the magnitude and detail level of of the LST and SUHI across regions. The analyses were focused on regional (in the north region of HCMC) and local (in districts belonging HCMC) levels, respectively. The LST were retrieved from the data of Landsat TM, ETM and OLI\&TIRS during 1995-2015 using Planck's law with the emissivity correction. Higher LST was concentrated in the inner city and districts of the northen city. LST threshold was chosen as above $35^{\circ} \mathrm{C}$ and was used to calculate the magnitude of SUHI on the north region of HCMC. It was found that, two distinct SUHIs formed in the study area. The first huge SUHI was formed in the urban core, accounted for approximately $18 \%$ compared to the total area of the north region of HCMC. The second SUHI was detected in the eastern part of HCMC, with the area expansion in 9 times within 20 years. The study has clarified that the formation of UHI was due to human's impact and urbanization

Many studies have also proved negative impact of UHI on life quality in urban environment. Therefore, from the aforementioned results, studies have proposed certain solution to lower the heat proliferation process during urbanization, so as to develop a sustainable urban.

Acknowledgments: This research is funded by Vietnam National Foundation for Science and Technology Development (NAFOSTED) under grant number 105.99-2012.12.

Author Contributions: All three authors significantly contributed to the scientific study and writing.

Conflicts of Interest: The authors declare no conflict of interest

\section{References}

1. Carlson, T., \& Ripley, D. On the relation between NDVI, fractional vegetation cover and leaf area index. Remote sensing of Environment, 1997, 62, 241-252.

2. EPA. The Encyclopedia of Earth. Available online: http://www.eoearth.org/view/article/153461/, 2012

3. Gillespie, A., Rokugawa, S., Hook, S., Matsunaga, T., \& Kate, A. Temperature / Emmisivity separation algorithm theoritical basis document, version 2.4. ATBD-AST-05-08, Prepared under NASA contract NAS5-31372, 1999

4. Gupta, R. Remote Sensing Geology. Germany: Springer -Verlag Berlin Heidelberg, 1991

5. Ho Tong Minh Dinh, Le Van Trung, Tran Thi Van. Surface Emissivity in Determining Land Surface Temperature, International Journal of Geoinformatics, 2007, 3 (4)

6. Jones P.D., Groisman P.Y., Coughlan M., Plummer N., Wang W.C., Karl T.R. Assessment of urbanization effects in time-series of surface airtemperature over land. Nature, 1990, 347:169-72

7. Kalnay E, Cai M. Impact of urbanization and land-use change on climate, Nature, 2003, 423:528-31

8. Le Van Trung, Nguyen Thanh Minh. Mapping Land Surface Temperature (LST) from Satellite Imageries. Case Study in Hochiminh City. Proceedings of the International Symposium GIS-IDEAS 2006, 9-11 November 2006, Ho Chi Minh City, Vietnam, 93-99

9. Li, Z.L., Becker, F., Stall, M.P. and Want, Z. Evaluation of Six Methods for Extracting Relative Emissivity Spectra from Thermal Infrared Images, Remote Sensing of Environment, 1999, 69, 197-214 
10. Lo, C. P., Quattrochi, A., D., \& Luvall, J. C. Application of high-resolution thermal infrared remote sensing and GIS to assess the urban heat. Remote Sensing of Environment, 1997, 18, 287-304.

11. Lougeay, Brazel, \& A.\& Hubble, M. Monitoring intraurban temperature patterns and associated land cover in Phoenix, Aizona using Landsat thermal data. Geocarto International, 1996, 11(4), 79-90.

12. Nguyen Duc Hoa. The process of urbanization in Saigon - HCMC from 1860 to 2008, and the impact on the socio-economic development of the city. Proceedings of the 3th International Workshop "Vietnam Study". Session: Urban and Urbanization, 310-327, 2010

13. Nguyen Thi Tuyet Mai. Research on the impact assessment of urban heat islands on the air quality by remote sensing method, Graduate Thesis, Ho Chi Minh City University of Technology, 2016

14. Markham, B.L. and Barkewr, J.L. Landsat MSS and TM Post Calibration Dynamic Ranges, Exoatmospheric Reflectance and at-satellite Temperatures. EOSAT Landsat Technical Note , 1986, 1, 3-8.

15. Pham Hong Cuc. Remote sensing application to study of the impact of urban development to thermal environment for northen part of Ho Chi Minh City, Graduate Thesis, Ho Chi Minh City University of Technology, 2014

16. Pham Van $\mathrm{Cu}$ and Hiroshi Watanabe. Use of Thermal Infrared Channels of Aster to Evaluate The Land Surface Temperature Changes of an Urban Area in Hanoi, Vietnam, Proceedings of the International Symposium GIS-IDEAS 2004, 85-90, Hanoi, Vietnam, 16-18 September, 2004

17. Tran H., Yasuoka Y. Monitoring Urban Surface from Space: Case Study of Hochiminh City and Surrounding Region, Proceedings of the International Symposium on Geoinformatics (GIS-IDEAS 2002), pp. 1-7, Hanoi, Vietnam, 25-28 September 2002

18. Tran Tan Vinh. The problem of urbanization and sustainable development in HCMC. Available online: http://www.hids.hochiminhcity.gov.vn/c/document_library/get_file?uuid=4f09433f-fd12-478e-8644db722890e968\&groupId=13025, 2005

19. Tran Thi Van. Thermal remote sensing applications to examine characteristics of urban surface temperature with the distribution of land cover types at HCMC. Journal of Science and Technology, Vietnam National University Publishing House, 2006, 9, 70-74

20. Tran Thi Van, Hoang Thai Lan and Le Van Trung. Research on the change of urban surface temperature under the impact of the urbanization process in Ho Chi Minh City by remote sensing. Journal of Earth sciences, 2011, 33(3), 347-359.

21. Valor, E., \& Caselles, V. Mapping Land Surface Emissivity from NDVI: Application to European, African and South American Areas. Remote Sensing of Environment, 1996, 57, 167-184.

22. Van de Griend, A., \& Owe, M. On the relationship between thermal emissivity and the normalized difference vegetation index for natural surfaces. Int. J. Remote Sensing, 1993, 14(6), 1119-1131

23. Voogt, J. A., \& Oke, T. R. Thermal remote sensing of urban climate. Remote sensing of Enviroment, 86 2003, 3, 370-384.

24. Weng, Q., Lu, D., \& Schubring, J. Estimation of land surface temperature-vegetation abundance relationship for urban heat island studies. Remote Sensing of Environment, 2004, 89, 467-483

25. Weng, Q. Thermal infrared remote sensing for urban climate and environmental studies: methods, applications, and trends. ISPRS Journal of Photogrammetry and Remote Sensing, 2009, 64 (4), 335-344

26. Yang, S., Zhang, M., Zeng, R. The urban heat island effect of Guangzhou. Journal of South China, Normal University, 1984, 2, 35-45

(C) 2017 by the authors; licensee Preprints, Basel, Switzerland. This article is an open access article distributed under the terms and conditions of the Creative Commons by Attribution (CC-BY) license (http://creativecommons.org/licenses/by/4.0/). 